\title{
Resources needed for US CDC's support to the response to post-epidemic clusters of Ebola in West Africa, 2016
}

\author{
Cristina Carias ${ }^{1 *}$, Bishwa B. Adhikari ${ }^{1}$, Fatima Ravat ${ }^{2}$, Martin I. Meltzer ${ }^{1}$ and Barbara J. Marston ${ }^{2}$
}

\begin{abstract}
Background: West African countries Liberia, Sierra Leone, and Guinea experienced the largest and longest epidemic of Ebola virus disease from 2014 to 2016; after the epidemic was declared to be over, Liberia, Guinea, and Sierra Leone still experienced Ebola cases/clusters. The United States Centers for Disease Control and Prevention (US CDC) participated in the response efforts to the latter Ebola clusters, by assisting with case investigation, contact identification, and monitoring. This study aims to estimate the cost to the US CDC of responding to three different Ebola clusters after the end of the Ebola epidemic in 2015: i) Sierra Leone, Tonkolili (Jan 2016, 2 Ebola cases, 5 affected regions); ii) Guinea, Nzerekore (Mar-May 2016, 10 Ebola cases, 2 affected regions); iii) Liberia, Somali Drive (Mar 2016, 3 Ebola cases, 1 affected region).

Main text: After interviewing team members that had participated in the response, we estimated total costs (expressed in 2016 US Dollars [USD]), where total costs correspond to travel costs, deployed personnel costs, costs to prepare for deployment, procurement and interagency collaboration costs, among others. We also estimated cost per cluster case (corresponding to the total costs divided by the total number of cluster cases); and cost per case-affected-region (equal to the total costs divided by the product of the number of cases times the number of regions affected). We found that the response cost varied sixteenfold between USD 113166 in Liberia and USD 1 764271 in Guinea, where the main cost drivers were travel and personnel costs. The cost per cluster case varied tenfold between 37722 in Liberia (three cases) and USD 347226 in Sierra Leone, and the cost per case-affectedregion varied threefold between USD 37722 in Liberia and USD 88214 in Guinea.
\end{abstract}

Conclusions: Costs vary with the characteristics of each cluster, with those spanning more regions and cases requiring more resources for case investigation and contact identification and monitoring. These data will assist policy makers plan for similar post-epidemic responses.

Keywords: Ebola cluster, Cost, Emergency response, Post-epidemic

\section{Multilingual abstracts}

Please see Additional file 1 for translations of the abstract into the five official working languages of the United Nations.

\section{Background}

From 2014 to 2016, West Africa experienced the largest and longest epidemic of Ebola virus disease (EVD). Over

\footnotetext{
* Correspondence: vnn9@cdc.gov

${ }^{1}$ National Center for Emerging and Infectious Zoonotic Diseases, Centers for Disease Control and Prevention, 1600 Clifton Road, MS C18, Atlanta, GA 30329-4027, USA

Full list of author information is available at the end of the article
}

28500 cases and 11300 deaths were reported to the World Health Organization (WHO) from Guinea, Sierra Leone and Liberia [1]. After the WHO declarations of the end of continuous transmission each country experienced additional EVD cases/clusters involving up to 13 infected individuals [2]. Such clusters represented a threat of wider dissemination and therefore a threat for global health security. Thus, public health officials in each country mounted responses aided in part by the United States Centers for Disease Control and Prevention (US CDC), where the CDC's main inputs related to case investigation and contact identification and monitoring.

(c) The Author(s). 2018 Open Access This article is distributed under the terms of the Creative Commons Attribution 4.0 International License (http://creativecommons.org/licenses/by/4.0/), which permits unrestricted use, distribution, and 
To aid planning for future such operations involving the $\mathrm{CDC}$ or other international organizations, we analysed costs, from the perspective of the CDC, of emergency responses to three clusters: i) Sierra Leone, Tonkolili (Jan 2016; two Ebola cases; five affected regions); [3] ii) Guinea, Nzérékoré (Mar-May, 2016; ten Ebola cases; two affected regions); [4] iii) Liberia, Somali Drive (Mar, 2016; three Ebola cases; one affected region) [5]. Whereas these clusters and the respective public health responses have previously been reported $[6,7]$, we quantify here the resources used in these responses.

\section{Methods}

We assessed resource usage during the responses by consulting the teams involved in the response, since specific costs are managed by different centres inside CDC. Such costs are limited to the time scope of the cluster and/or personnel deployment. We consulted in-country CDC team members that were or had been stationed in West Africa and had been in charge of the cluster response. We also consulted personnel located in the Emergency Operations Center in the CDC headquarters in Atlanta responsible for setting up travel, and providing logistical materials for the deployed personnel. We thus interviewed 21 Emergency Operations Center and in-country $\mathrm{CDC}$ team members to obtain data on the three emergency responses under study. Since the study was performed from the perspective of the CDC, we did not include resources expended by the Ministries of Health in the affected countries or by other supporting partners.

We included travel costs; deployed personnel time (in hours and wages); funds necessary for collaboration with other agencies; costs needed to for procured materials (such as Rapid Diagnostic Tests), if required; cost of local hires in the region where the response took place; cost of vaccination and medical clearance costs required to personnel preparing to be deployed; transport and other logistical costs such as fuel and security, if required; communication equipment/service for deployed personnel; planning and scheduling travel costs ("backstage costs"); and costs required to reimburse partners for support given for the cluster in terms of personnel and resources for emergency evacuation procedures, if required. When addressing personnel compensation, we considered personnel deployed from the CDC's Atlanta headquarters, personnel from other agencies assisting in the response via an interagency agreement, and CDC teams aggregated from already stationed and CDC-contracted personnel in the country of the response (i.e., CDC in-country teams). We did not include the costs of personnel stationed in Atlanta that did not travel or was not involved in travel preparation.

We calculated total costs. Given wide variability in total costs, we also estimated cost per cluster case, equal to the total costs divided by the total number of cluster cases; and cost per case-affected-region, which is equal to the total costs divided by the product of the number of cases times the number of regions affected. That is, if there are 10 cases spread over two regions, one would divide total costs by 20. To allow for comparison among countries, we expressed costs in US Dollars (USD) in 2016 prices (USD 2016).

\section{Results}

The cost of responding to an Ebola cluster varied widely between responses, ranging from USD 113 thousand in Liberia, to USD 1800 thousand in Guinea (Table 1; Fig. 1). In Sierra Leone, response costs were USD 694 452 (Table 1). Regarding deployed-person hours, they varied from $250 \mathrm{~h}$ in Liberia to over 5 thousand deployed-person hours for the responses to clusters in Sierra Leone and Guinea; with only Guinea requiring additional personnel from other agencies. In addition, Liberia required $2040 \mathrm{~h}$ from CDC in-country teams, with Guinea and Sierra Leone requiring 5213 and 1989 person-hours, respectively.

Across all clusters, the biggest drivers of response costs were travel costs (16\% in Liberia, 31\% in Guinea, and $50 \%$ in Sierra Leone) and personnel costs (11\% in Liberia, $22 \%$ in Guinea, up to $40 \%$ in Sierra Leone). These costs are related to the need to deploy personnel expert in epidemiology to perform case investigation, contact identification and monitoring, which were CDC's main contributions to response (Table 1). Travel costs increase proportionally with the number of responders deployed from Atlanta, and were related to the high costs of air travel and lodging. Deployed personnel costs varied between USD 11988 in Liberia (three cases, one affected region) and USD 392910 in Guinea (ten cases, two affected regions). In Sierra Leone (two cases, five affected regions), personnel costs were USD 278 110. Since personnel costs are related to the need for contact tracing, they increase with the complexity of the cluster, that is, with the number of cluster cases and/or regions affected by the cluster.

Other significant costs included are interagency collaboration costs (USD 459000 in Guinea, or $26 \%$ of total costs in this country), which are specific to the particularities of each cluster. The need for these resources increases very rapidly with the number of cases and geographic spread of the cluster. For the responses studied, the complexity of the cluster in Guinea (which included ten cases over two different regions) demanded an additional number of resources to do contact tracing and epidemiologic investigations.

Additionally, the resources required for some responses included procurement costs for rapid diagnostics tests (RDTs) (between USD 29700 in Liberia, 26\% of 


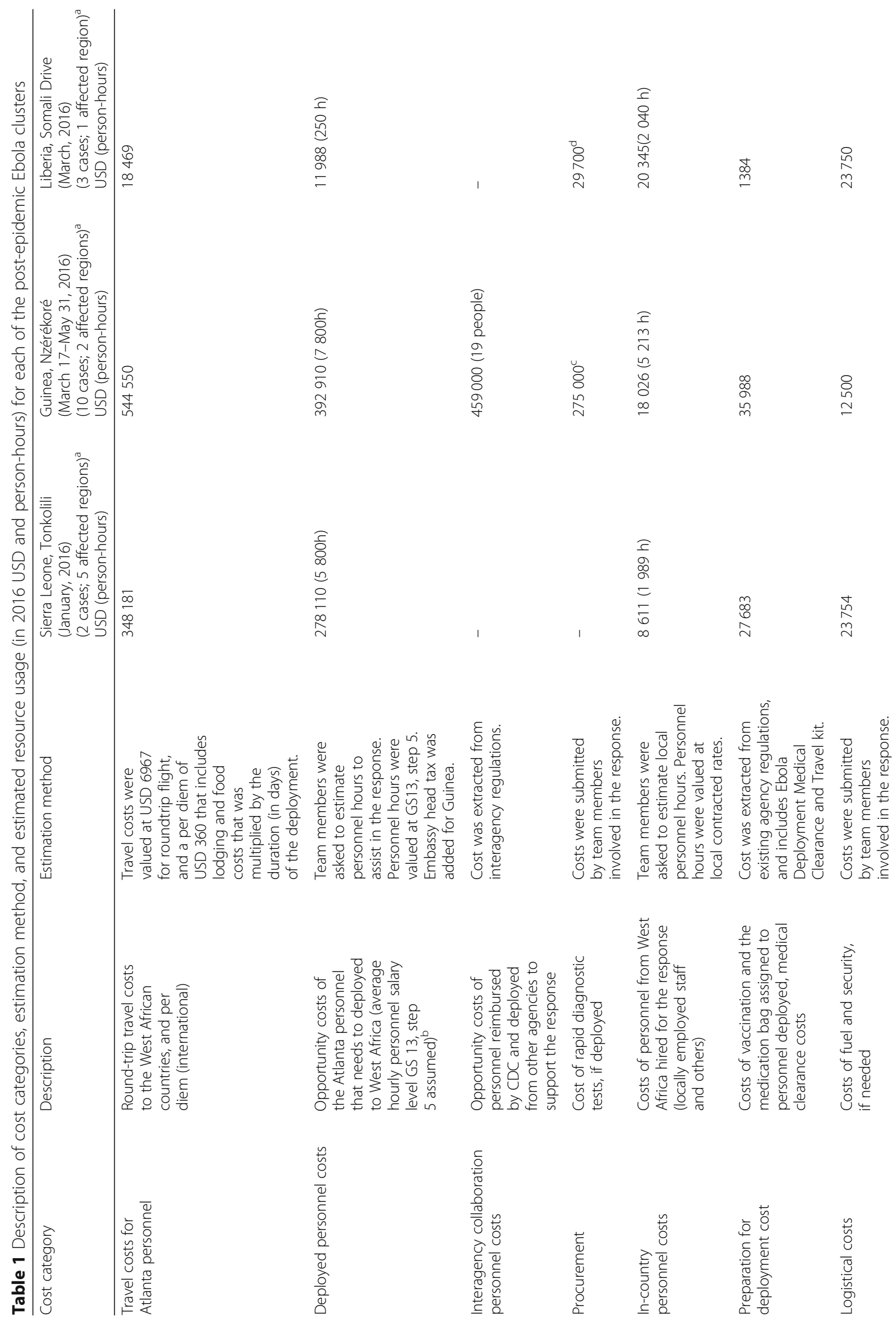




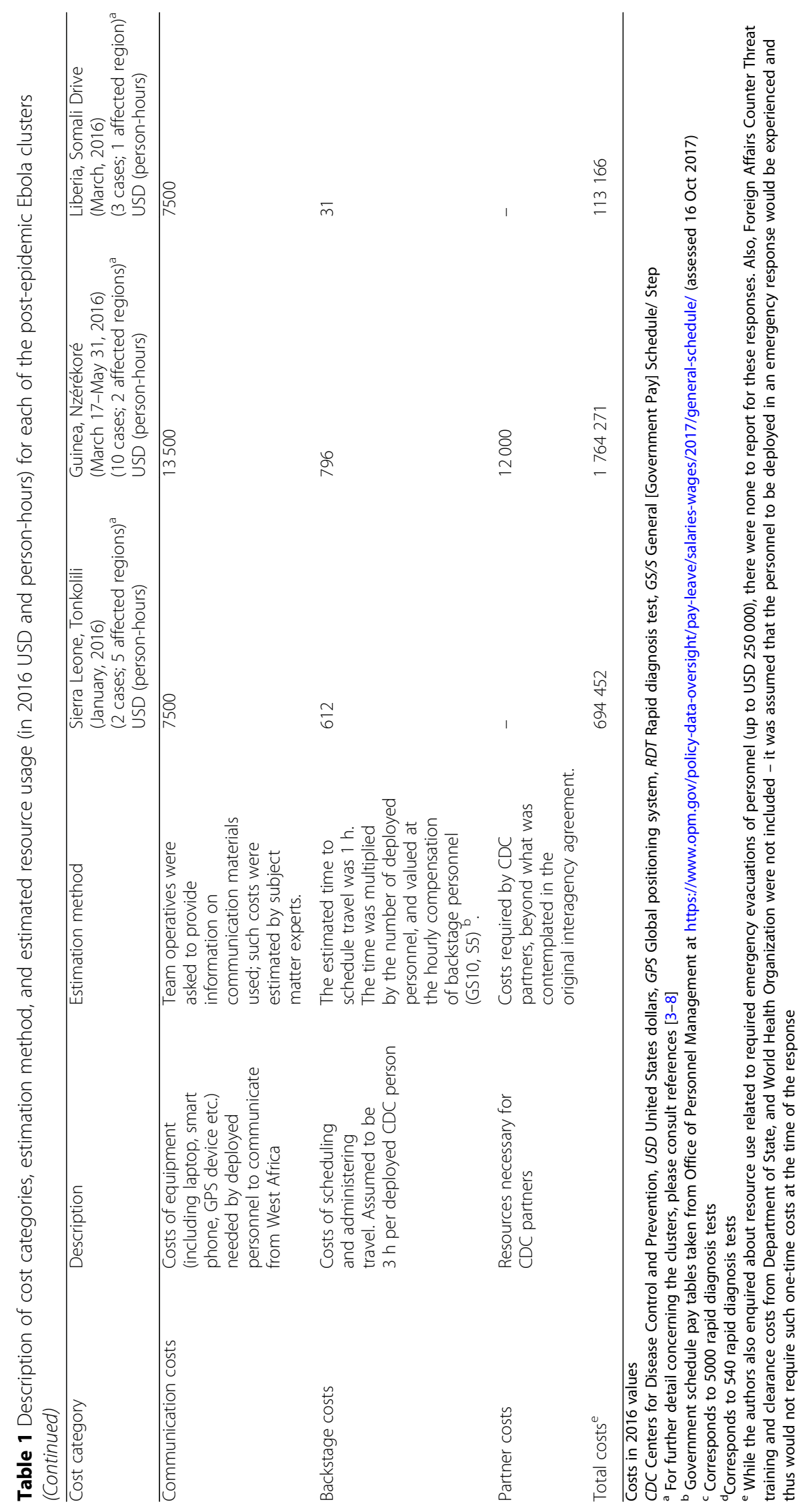




\section{US Dollars (thousands) per cost categories}

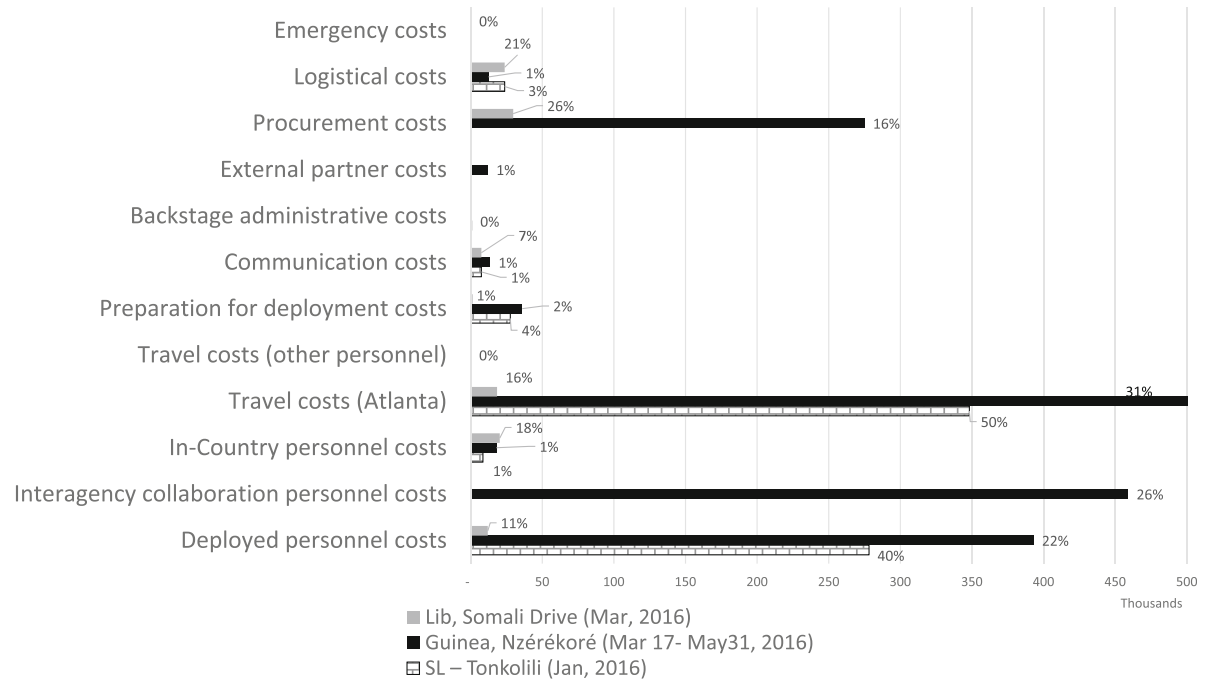

Fig.1 Bar chart representing the magnitude of different cost categories, (in 2016 USD, and as precentage of total costs) for each of the post-epidemic Ebola clusters analysed. Legend: The figure represents the magnitudes of different cost categories. The vertical axis includes the names of all cost categories, while the horizontal axis represents the resources used per category (in thousands of dollars). The different bars correspond to a different post-epidemic Ebola cluster (black: Guinea, Nzérékoré; grey: Liberia, Somali Drive; dotted: Sierra Leone, Tonkolili). Note that the black bar for travel costs for Guinea was truncated (the absolute value was USD 544 550). USD: United States dollars

total costs; and USD 275000 in Guinea, or 16\% of total costs; none in Sierra Leone). The need for RDTs is judged on a case-by-case basis; whether more RDTs are required is a function of the numbers of possibly exposed persons and suspected cases as well as the diagnostic testing algorithm adopted.

In what concerns the resources necessary to prepare for deployment (cost of vaccination, medical clearance), they varied from USD 1384 in Liberia (1\% of total costs) to USD 35988 in Guinea (2\% of total costs); with costs in Sierra Leone (USD $27683 ; 4 \%$ of total costs) also high given the number of regions affected by the cluster and the consequent need to deploy more personnel. Finally, it was also necessary to take into account logistical costs (fuel and security) which varied from almost USD 24000 in Liberia and Sierra Leone to USD 12500 in Guinea (these costs correspond to $21 \%$ of total costs in Liberia; and less than $3 \%$ of total costs in Sierra Leone and Guinea). Such costs depend on the geographic characteristics of the region where the cluster takes place (whether cases are spread over a wide area or not), and on the need or not to hire an extra security detail. Thus, they depend more on the context where the cluster unfolds then on the characteristics of the cluster itself.

The cost per cluster case varied almost tenfold between 37722 in Liberia (three cases) and USD 347226 in Sierra Leone (two cases); in Guinea, cost per case was USD 176 427. The cost per case and affected region varied almost threefold between USD 37722 in Liberia (three cases, one affected region; three cases-affected-regions) and USD 88 214 in Guinea (ten cases, two affected regions; 20 cases-affected-regions); it was USD 69445 in Sierra Leone (two cases, five affected regions; ten cases-affected regions).

\section{Discussion}

For the clusters studied, the cost per case-affected-region varied almost threefold between USD 37722 in Liberia and USD 88214 in Guinea. Total costs varied sixteenfold between USD 113166 in Liberia and USD 1764271 in Guinea. This study illustrates the broad range of resources needed for responding to an international emergency response. The large differences in estimates of cluster costs seem to be due to varied response activity, which depends on the particular characteristics of the cluster (number of cases and number of affected regions). The need for resources seems to increase with both the number of cases and with the geographical dispersion of the cases, with a higher than linear increase on costs per case-affected region.

Note, however, that we did not include costs of personnel that did not travel or were not involved in travel preparation. We also did not include costs from other partners, such as other international organizations and Ministries of Health. That is, the costs presented in this manuscript represent the costs to respond to Ebola clusters, from the perspective of the CDC, and are thus limited to a portion of total response costs. To calculate total 
costs, the resources used by different partners would also have to be taken into account. Countries that increase their capacity to detect-and-respond to clusters may also experience similar types of response costs, scaled to the size of their Ministries of Health/response teams and the specific requirements for the teams (namely, travel and security requirements). In addition, costs were estimated via interviews; given that we were unable to consult logistical records such as receipts, there may be cost under-reporting. We have tried, however, to collect data for different clusters in order to be able to appreciate the variation of response costs with cluster characteristics (number of cases and regions affected).

\section{Conclusions}

This study is a first step towards quantifying resource usage during the response to an emergent disease outbreak. We found that total response costs varied sixteenfold for the studied outbreaks; they varied threefold by case and region affected. This suggests that the resources required to respond to clusters vary crucially with the characteristics of each outbreak, namely the regions affected and the total number of cases. As a result, a comprehensive assessment of the characteristics of the cluster and regions affected is necessary to gauge the total means necessary to the response. This information is useful for policy makers considering the resources required to mount emergency responses and thereby enhance global health security.

\section{Additional file}

Additional file 1: Multilingual abstracts in the five official working

languages of the United Nations. (PDF $192 \mathrm{~kb}$ )

\section{Abbreviations}

CDC: Centers for Disease Control and Prevention; EVD: Ebola viral disease; US: United States; USD: United States dollars; WHO: World Health Organization

\section{Acknowledgements}

We would like to acknowledge: Mame Akyeampong; Edward Rouse; Jeffrey Bryant; Daniel Martin; Brittany Sunshine; Erika Meyer; and Suzanne Friesen for crucial information concerning costs and resource usage.

The findings and conclusions in this report are those of the authors and do not necessarily represent the official position of the Centers for Disease Control and Prevention.

\section{Funding}

This study was developed as party of the job duties of the authors, and no special funding was required for this study.

\section{Availability of data and materials}

All the data necessary to reproduce the results can be found in the manuscript's tables.

\section{Authors' contributions}

CC and BBA performed the calculations. CC wrote the first draft of the manuscript. BM and FR coordinated with the country teams to provide the data inputs. BM and MIM, provided senior guidance. All authors read, made significant edits to the first version, and approved the final manuscript.
Ethics approval and consent to participate

Not applicable.

\section{Consent for publication \\ Not applicable.}

\section{Competing interests}

The authors declare that they have no competing interests.

\section{Author details}

${ }^{1}$ National Center for Emerging and Infectious Zoonotic Diseases, Centers for Disease Control and Prevention, 1600 Clifton Road, MS C18, Atlanta, GA 30329-4027, USA. ${ }^{2}$ Center for Global Health, Centers for Disease Control and Prevention, Atlanta, USA.

Received: 21 March 2018 Accepted: 7 September 2018

Published online: 12 October 2018

References

1. Ebola outbreak 2014-2015: World Health Organization; 2017. Available from: http://www.who.int/csr/disease/ebola/en/. Accessed 16 Oct 2018.

2. CDC's ongoing work to contain Ebola in West Africa. Available from: https:// www.cdc.gov/vhf/ebola/pdf/cdcs-ongoing-work.pdf. Accessed 16 Oct 2018.

3. WHO Ebola Situation Report - 20 January 2016. Available from: http://apps. who.int/iris/bitstream/10665/204172/1/ebolasitrep_20Jan2016_eng.pdf?ua= 1. Accessed 16 Oct 2018

4. WHO Ebola Situation Report - 26 May 2016 [April 28, 2017]. Available from: http://apps.who.int/iris/bitstream/10665/206924/1/ebolasitrep_26May2016_ eng.pdf. Accessed 16 Oct 2018

5. New positive case of Ebola virus disease confirmed in Liberia. Available from: http://www.who.int/mediacentre/news/statements/2016/liberia-ebola/ en/. Accessed 16 Oct 2018

6. Diallo B, Sissoko D, Loman NJ, Bah HA, Bah H, Worrell MC, et al. Resurgence of Ebola virus disease in Guinea linked to a survivor with virus persistence in seminal fluid for more than 500 days. Clin Infect Dis. 2016;63(10):1353-6.

7. Alpren C. Ebola virus disease cluster-northern Sierra Leone, January 2016. Morb Mortal Wkly Rep. 2016;65.

8. Ebola Situation Report, 30 March 2016: World Health Organization. Available from: http://apps.who.int/ebola/current-situation/ebola-situation-report-30march-2016. Accessed 16 Oct 2018.
Ready to submit your research? Choose BMC and benefit from:
- fast, convenient online submission
- thorough peer review by experienced researchers in your field
- rapid publication on acceptance
- support for research data, including large and complex data types
- gold Open Access which fosters wider collaboration and increased citations
- maximum visibility for your research: over $100 \mathrm{M}$ website views per year
At BMC, research is always in progress.
Learn more biomedcentral.com/submissions 